\title{
Estimating the Number of Sex Workers in South Africa: Rapid Population Size Estimation
}

\author{
Tracey L. Konstant $\cdot$ Jerushah Rangasami • \\ Maria J. Stacey • Michelle L. Stewart • \\ Coceka Nogoduka
}

Published online: 13 January 2015

(C) Springer Science+Business Media New York 2015

\begin{abstract}
Although recognized as a vulnerable population, there is no national population size estimate for sex workers in South Africa. A rapid sex worker enumeration exercise was undertaken in twelve locations across the country based on principles of participatory mapping and Wisdom of the Crowd. Sites with a range of characteristics were selected, focusing on level of urbanisation, trucking, mining and borders. At each site, sex worker focus groups mapped local hotspots. Interviews with sex workers at identified hotspots were used to estimate the numbers and genders of sex workers working in each. Estimates provided in the literature were combined with enumeration exercise results to define assumptions that could be applied to a national extrapolation. A working estimate was reached of between 131,000 and 182,000 sex worker in South Africa, or between 0.76 and $1 \%$ of the adult female population. The success of the exercise depended on integral involvement of sex worker peer educators and strong ethical considerations.
\end{abstract}

T. L. Konstant $(\bowtie) \cdot$ M. L. Stewart

Impact Consulting/Independent, Cape Town, South Africa

e-mail: tlk@mweb.co.za

J. Rangasami

Impact Consulting, Cape Town, South Africa

M. J. Stacey

Sex Workers Education and Advocacy Trust, Cape Town,

South Africa

e-mail: Maria.Stacey@sweat.org.za

C. Nogoduka

FHI360, South African National AIDS Council, Pretoria,

South Africa
Keywords Sex worker - Key population - Enumeration · South Africa · Participatory · Mapping

\section{Introduction}

HIV prevalence amongst female sex workers in South Africa is estimated to be as high as $59.6 \%$ [1]. Sex workers are among the most hidden, least understood and most marginalised people in South Africa. Largely due to criminalisation, which exacerbates an extremely vulnerable work life, sex workers face severe rights abuse, regular violence, public stigma and discrimination, and have minimal access to justice. They may be beaten or raped by their clients and the police. They are regularly not paid for services rendered, with their objections frequently leading to violence. They are likely to be left at the roadside a distance from their homes. Sex workers also describe being publicly identified and insulted by health workers, and are less likely to seek HIV and sexually transmitted infections (STI) services where their status, profession and health conditions are a source of verbal abuse. In the most severe settings, although not widespread in most parts of South Africa, sex workers may be subjugated to controllers through drug addiction, drug debt and force.

While these conditions are undoubtedly difficult, the Sex Worker Education and Advocacy Task Force (SWEAT) is an education and advocacy organisation that strongly promotes a respectful acknowledgement of the professional choices made by the majority of sex workers. SWEAT advocates that abusive, exploitative and under-age sex work can only be identified and addressed with decriminalisation of consenting, adult, professional sex work, advocacy for health and legal rights, and recourse to justice in cases of rape, violence and abuse. Although many sex workers yearn 
for alternative or additional forms of employment, they do not wish to be rescued from their profession. They would prefer to see their profession and their rights recognised.

Evidence-based interventions that support the sexual and reproductive health rights of sex workers, while enabling reduced HIV infection rates, are major components of an effective national HIV response under the South African National AIDS Council's (SANAC) "National Strategic Plan for HIV, TB and STIs" (NSP) [2]. SANAC has prioritised responses to key populations in the NSP, aligned with a strong international drive to address the needs of most-at-risk populations [3, 4]. Planning, monitoring, evaluation and costing of integrated interventions and services depends on estimates of the sizes of hidden populations, including sex workers and other key populations. Mapping and population distribution studies enable a locally relevant, properly costed, responsive and relevant, targeted response to be formulated within national planning.

Relatively little is published that describes tested methods for estimating sex worker populations or data for population estimates in Africa [5]. Up to now, published population estimates have either focused on localised areas within South Africa [6,7] or have used published data from other countries to provide national estimates [8]. Vandepitte [9] provides useful estimates for a selection of African cites for comparison, but does not include data for South African sites.

Having identified a clear and urgent need for field-tested information at a national scale, SANAC entered into partnership with SWEAT to commission and guide a rapid enumeration of the sex worker population [10].

A method was developed based on literature and consultation (T. Lane, 2013, personal communication). Instruments and processes were tested in the field, and refined through piloting. The resulting rapid field assessment is closely aligned to a protocol that has since been distributed by the Joint United Nations Programme on HIV/AIDS (UNAIDS) [3]. The method draws on 'Wisdom of the Crowd' [11, 12] and respondent-driven census [13]. It integrates mapping [13, 14], focus group discussions and interviews. At all stages, the involvement of sex workers and sex work peer educators was critical to effectiveness. The method also follows concepts of geographical zoning and aggregation, which produced national estimates for Pakistan [15], and variations on concepts of snowball sampling for hidden populations [16].

The method contrasts with capture-recapture methods $[17,18]$ and the use of clients and sex work contact as a primary data source of sex worker population [19], instead using a far stronger emphasis on informant knowledge as evidence.

\section{Methods}

\section{Defining Sex Work}

For their purposes, SANAC and SWEAT define sex work as the regular professional exchange of sex for cash, defining their target group as sex workers who identify themselves as such. This includes self-identified sex workers who are under the age of 18. Child sex-workers pose a particularly delicate challenge for a sex work outreach organisation. If they are approached as victims of abuse, they are less likely to be accessible for support, education and access to rights. Nevertheless, their needs and ideally their removal from under-age sex work are an important ideal. In a strongly pragmatic approach, SWEAT and its partners acknowledge that a critical or interventionist approach to under-age sex workers is likely to exclude them, and render them even more vulnerable to abuse and exploitation, and most organisations offer youthcustomised, but non-judgemental education and outreach interventions.

\section{Mobile Men}

The concept of mobile populations, and particularly mobile men, is accepted as a strong determinant for HIV vulnerability and for increased concentrations of sex workers [4]. These are men who are in transit or away from home, such as migrant workers in construction or mining, truck drivers, and seasonal agricultural workers. Census data manipulated by the Council for Scientific and Industrial Research (CSIR) provide population statistics for employment in the mining and transport industries. Based on the assumption that mobile male population is linked with sex worker population, these population data were used both to stratify selected sites, and to extrapolate enumeration data.

\section{Selection of Sites}

Although limited resources restricted the exercise to a severely inadequate 12 sites (Table 1), the approach was completely new in the country, and broached largely unexplored methods, target groups and results.

The following site selection criteria were applied.

\section{Partner Organisations}

A practical factor for site selection was the presence of a sex worker network through a partner organisation, providing access to sex worker informants. In sites where no sex work contact existed, access to sex workers was feasible with the help of sex worker peers from other areas, 
Table 1 List of enumeration sites and key characteristics

\begin{tabular}{|c|c|c|c|}
\hline Province & Sampled place name & $\begin{array}{l}\text { Population }(\mathrm{P})^{\mathrm{a}} \\
\text { AFP }^{\mathrm{b}} \\
\text { Miners (M) }\end{array}$ & Geographic character and rationale for selection as a site \\
\hline Gauteng & $\begin{array}{l}\text { Johannesburg } \\
\left(\operatorname{CSIR}^{\mathrm{c}} \text { City Region) }\right.\end{array}$ & $\begin{array}{l}\mathrm{P}=4,434,816 \\
\mathrm{AFP}=1,590,499 \\
\mathrm{M}=9,005\end{array}$ & $\begin{array}{l}\text { Largest metropolitan area } \\
\text { Trucking destination } \\
\text { Strong partner organisations } \\
\text { Hillbrow and Central Johannesburg have the densest } \\
\text { and most open sex work industries in the country }\end{array}$ \\
\hline Western Cape & $\begin{array}{l}\text { Cape Town } \\
\text { (CSIR City Region) }\end{array}$ & $\begin{array}{l}\mathrm{P}=3,736,199 \\
\mathrm{AFP}=1,327,630 \\
\mathrm{M}=1,737\end{array}$ & $\begin{array}{l}\text { Second largest metropolitan area } \\
\text { Trucking destination and port } \\
\text { Known high levels of sex work and sex tourism } \\
\text { Strong partner organisations }\end{array}$ \\
\hline KwaZulu Natal & $\begin{array}{l}\text { eThekwini/Durban } \\
\text { (CSIR City Region) }\end{array}$ & $\begin{array}{l}\mathrm{P}=3,442,388 \\
\mathrm{AFP}=1,227,539 \\
\mathrm{M}=2,895\end{array}$ & $\begin{array}{l}\text { Third largest metropolitan area } \\
\text { Trucking destination and port }\end{array}$ \\
\hline Eastern Cape & $\begin{array}{l}\text { Buffalo City/East London } \\
\text { (CSIR city region) }\end{array}$ & $\begin{array}{l}\mathrm{P}=512,418 \\
\mathrm{AFP}=120,400 \\
\mathrm{M}=148\end{array}$ & Metropolitan area, trucking route and port \\
\hline Free State & $\begin{array}{l}\text { Mangaung/Bloemfontein } \\
\text { (CSIR City) }\end{array}$ & $\begin{array}{l}\mathrm{P}=474,105 \\
\mathrm{AFP}=167,178 \\
\mathrm{M}=555\end{array}$ & $\begin{array}{l}\text { Metropolitan area, inland trucking route } \\
\text { Provincial capital and administrative centre } \\
\text { No partner organisation, but personal } \\
\text { contacts through a SWEAT peer educator }\end{array}$ \\
\hline North-West & $\begin{array}{l}\text { Rustenburg } \\
\text { (CSIR City) }\end{array}$ & $\begin{array}{l}\mathrm{P}=399,931 \\
\mathrm{AFP}=126,335 \\
\mathrm{M}=54,655\end{array}$ & $\begin{array}{l}\text { Mining area and trucking route } \\
\text { Surrounded by dense rural nodes (vast, semi-rural, } \\
\text { contiguous, under-resourced villages) }\end{array}$ \\
\hline Mpumalanga & $\begin{array}{l}\text { Emalahleni/Witbank } \\
\text { (CSIR Regional Centre) }\end{array}$ & $\begin{array}{l}\mathrm{P}=299,213 \\
\mathrm{AFP}=98,838 \\
\mathrm{M}=4,023\end{array}$ & Mining area and trucking route \\
\hline Northern Cape & $\begin{array}{l}\text { Kimberley } \\
\text { (CSIR Regional Centre) }\end{array}$ & $\begin{array}{l}\mathrm{P}=226,554 \\
\mathrm{AFP}=78,309 \\
\mathrm{M}=761\end{array}$ & $\begin{array}{l}\text { Trucking route and mining } \\
\text { No partner organisation, but Cape Town peer has contacts } \\
\text { with sex workers there } \\
\text { Service town surrounded by sparsely populated rural areas }\end{array}$ \\
\hline Limpopo & $\begin{array}{l}\text { Thohoyandou } \\
\text { (CSIR Regional Centre) }\end{array}$ & $\begin{array}{l}\mathrm{P}=140,821 \\
\mathrm{AFP}=48,703 \\
\mathrm{M}=0\end{array}$ & $\begin{array}{l}\text { Remote town relatively distant from the nearest } \\
\text { major commercial centre } \\
\text { Provides a government administrative centre for the area }\end{array}$ \\
\hline Limpopo & $\begin{array}{l}\text { Musina } \\
\text { (CSIR Service Town) }\end{array}$ & $\begin{array}{l}\mathrm{P}=40,973 \\
\mathrm{AFP}=14,139 \\
\mathrm{M}=629\end{array}$ & Border town on trucking route \\
\hline Western Cape & $\begin{array}{l}\text { Beaufort West } \\
\text { (CSIR Service Town) }\end{array}$ & $\begin{array}{l}\mathrm{P}=32,887 \\
\mathrm{AFP}=10,888 \\
\mathrm{M}=0\end{array}$ & Small service town on a major trucking route \\
\hline KwaZulu Natal & $\begin{array}{l}\text { Pongola } \\
\text { (CSIR Service Town) }\end{array}$ & $\begin{array}{l}\mathrm{P}=31,982 \\
\mathrm{AFP}=10,362 \\
\mathrm{M}=0\end{array}$ & $\begin{array}{l}\text { Border town on trucking route, surrounded } \\
\text { by a densely populated rural area }\end{array}$ \\
\hline
\end{tabular}

\footnotetext{
${ }^{\text {a }}$ Statistics South Africa Census 2011

b Adult female population

${ }^{c}$ Centre for Scientific and Industrial Research place classification
}

but mapping was more difficult and less comprehensive. Sites were therefore selected on the basis of the availability and capacity of a peer-based partner organisation. With relatively few formal peer-support organisations in existence, the options for sites were limited and purposive, convenience sampling was used for site selection. 


\section{Provincial Distribution}

Sites were selected in all nine provinces.

\section{Large and Small Centres}

Sites ranged in population size, from under 32,000 in the smallest selected site, up to Johannesburg with a population of over 4 million.

\section{High Transmission Areas}

Most of the sites selected had high population proportions of mobile men, being connected with truck routes, mines or border towns.

\section{Place Types}

Various categories of place were selected using a place typology provided by the Centre for Scientific and Industrial Research (CSIR) such as 'city', 'regional centre', 'service town' or 'local town'. The categories were largely a reflection of urbanisation and population dispersal, and were used both for site selection and to define assumptions for national estimates.

\section{Preparation}

\section{The Field Team}

The team included one field leader and at least one sex worker guide. Sex worker guides were a critical component in the methodology, and are strongly recommended for all engagement with sex workers. Sex worker guides provide access, trust and local knowledge. They enabled the team to recognise sex work sites, find and engage with sex worker respondents. Peer guides are also sensitive to the concerns, immediate threats and situations facing sex workers during the contact, and are able to advise the team on appropriate responses in order to protect both the field team and sex worker participants.

SWEAT or a local partner organisation selected guides from among their sex worker peer educators. Guides were invited who were well-connected among sex workers and knew the area, and were reliable and committed to the needs of the team. Guides were introduced to the research purpose, the rationale of the outreach data collection process and the ultimate intentions for the data. They were then able to become valuable field assistants in all respects, helping with questioning, interpretation and probing.

The team leader was responsible for facilitating focus groups and guiding interviews, ensuring that data were correctly collected, managing logistics, ensuring ethical practice, and taking final decisions on process. Team leaders were recruited based on their experience working with vulnerable groups, experience in data collection in the field, ability in a range of languages and resilience to working at night in potentially difficult situations. An encouraging, non-judgemental attitude was essential, with an ability to engage constructively despite the sometimes traumatic conditions surrounding sex work, including young people, drugs, controllers and accounts of violence by respondents. Sex workers' stories can be harrowing, and the emotional capacity of field team members was a factor to consider when recruiting and during orientation.

\section{Piloting the Methodology and Training the Team}

The method was developed in Cape Town through a series of pilot exercises led by the design team, with the field staff and the Cape Town sex worker guides. The pilot served multiple purposes. Instruments, approaches and methods were refined substantially. The team received practical training, including detailed understanding of the process and tools, data collations expectations, basic map reading and map making, practice with interviewing and probing around the interview themes. In debrief sessions, the team reflected on experiences, refined their own attitudes to sex work, and discussed ethics and safety considerations, providing a well-rounded orientation to the field work to follow.

\section{Timing}

Several considerations were important in selecting the time at which sex work is most active. Sex work peaks over weekends and around the end of the month when clients have been paid. The summer months are busiest, with street-based sex work being uncomfortable in most parts of South Africa in winter. Many sex workers said that they visit their families during the Easter and Christmas holidays. Considering all of these factors, data collection was timed for the end of February 2013.

\section{Field Team Branding}

SWEAT has found branding to be valuable in protecting outreach workers from harassment, ensuring transparency of purpose and, over time, building trust and curiosity among sex workers to approach the organisation. The team was clearly branded using SWEAT t-shirts with slogans such as "sex work is work" and "decriminalise sex work". This ensured that the orientation of the visitors was clear, giving sex workers an opportunity to decide whether or not to interact while they were being approached. The branding 
provides an opportunity for a first stage of informed consent.

Hotspots generally include substantial groups of locally mobile sex workers, and individual identification and subsequent targeting by the police was unlikely. Sex workers are accustomed to being identified by clients, police and potential threats. They rapidly removed themselves if they saw the police during an interview. While the team was always aware of the risks of participants being targeted through the interaction, sex workers are skilled at avoiding unwanted contact, and took evasive action.

\section{Approaching Respondents}

Sex workers were approached first by the peer guide to ask for permission to be included in the process. The guide explained that the interview would take less than 5 minutes, that they would remain anonymous, and that they could stop the interview at any time. The purpose of the interview was described as providing information on the numbers of sex workers and where they worked, so that services could be improved to meet their needs. Once consent had been achieved, other team members approached, taking an informal and conversational approach to the questions.

Many sex workers were fearful at first contact and several refused to be approached, although enough were less anxious and were drawn by the branding and the interest being taken in their issues. Once reassured by the guide of the supportive intentions behind the exercise, many sex workers self-identified and were comfortable with being interviewed. Unaccustomed to being questioned in a constructive and respectful manner, respondents were often deeply appreciative and many provided abundant and detailed information about their lives and concerns.

\section{Data Collection Process}

\section{First Focus Group: Pre-mapping}

A focus group discussion (FGD) of sex workers was convened at the offices of the partner organisation in most cases. The group was generally connected with peer educators in the organisation, or their social circle.

The process used pre-printed maps of the target area, including street names if possible, and at least suburb names and major roads. The focus group was first oriented to landmarks, bearing in mind that participants may not all be familiar with maps. A sequence of questions was used to plot the distribution of sex workers across the known area (Table 2). The FGD captured the locations in which sex workers operate, or hotspots (Fig. 1), onto the printed map.

\section{Route Planning}

Visited hotspots were purposively sampled to include the range of sex work types and genders, taking into consideration the popularity of each location. In all but the largest sites all hotspots could generally be visited in a single, extended field work session. Most hotspots have clearly defined peak times. Using the map of hotspots and timing, routes were constructed that enabled as many hotspots as possible to be sequenced for visits at the time at which sex workers were most active.

\section{Onsite Interviews}

Informants included sex workers, brothel managers, barkeepers, club and bar bouncers, police officers, shop keepers, taxi drivers, controllers and any other local person able to observe the activities in the area. Interviews followed an approximate sequence of questions related to population size for the hotspot, and other hotspots known to the respondent, using a data collection instrument (Table 3). The field team spoke to as many different informants as could be found and moved away once a data saturation point had been met, when informants began to corroborate each other's estimates of the number of sex workers in the hotspot.

Notes were taken, although kept unobtrusive, ensuring engagement rather than a more intimidating and extractive formal research style of questioning. Once enumeration data had been collected, semi-structured interviews were continued with respondents who were interested, within the themes outlined in Table 3.

In the simplest counting exercises, apartment blocks of 15 floors, at 10 rooms per floor, and 2 sex workers per room, provide good quality easily estimated data. Alternatively, hotspots could be divided down to corners, street blocks or bars, in each of which sex worker numbers could be estimated.

Hotspot estimates became challenging if visits to highly populated hotspots took place at the wrong time of day, or on a quiet night of the week. Respondents found it very difficult to estimate numbers above about 20, and wide variation arose for larger numbers unless a direct count could be achieved. Another challenge was that sex workers may move along a stretch that sometimes included several hotspots, and questions around whether the same sex workers were being described for different hotspots were important in the interviews. In this case interviewers asked about movement, and reduced the given count across the related hotspots.

The most densely populated streets of central Johannesburg have three sex worker shifts a day of different people. A direct count on a late shift calculated groups of around 5-8 sex workers, clustered every 5-10 $\mathrm{m}$ along a $100 \mathrm{~m}$ block, or up to 100 sex workers along a block at a 
Table 2 Focus group mapping exercise question sequence

\begin{tabular}{ll}
\hline Approximate sequence of questions & Examples of appropriate questions
\end{tabular}

All known sites where sex work takes place.

Please show on the map all of the places you know where sex workers operate

For each identified hotspot:

The busiest times for sex work at each locality

At what times are there most sex workers at this hotspot?

(Responses, for example, the beach is busy in the afternoon as the clients are workers from the factory nearby; or sex workers arrive outside clubs after midnight)

The number of sex workers at each hotspot

About how many sex workers operate at this hotspot when it is very busy?

Is this hotspot more or less popular than others? Do the same sex workers move between these hotspots, or do they tend to stay in one area?

The types of sex work for each hotspot, including street-based, brothels, hotels, houses, bars, any other options

How do the sex workers find their clients at this hotspot, for example do they stand on the street, or work in the bars?

Or are there brothels or houses in this area?

The gender of sex workers, with female, male or transgender as the working distinctions

Depending on gender of respondent, are most sex workers who work here [girls]?

Where do the men work?

Where do the trans work?

Fig. 1 Example of a sex worker hotspot mapping exercise (Color figure online)

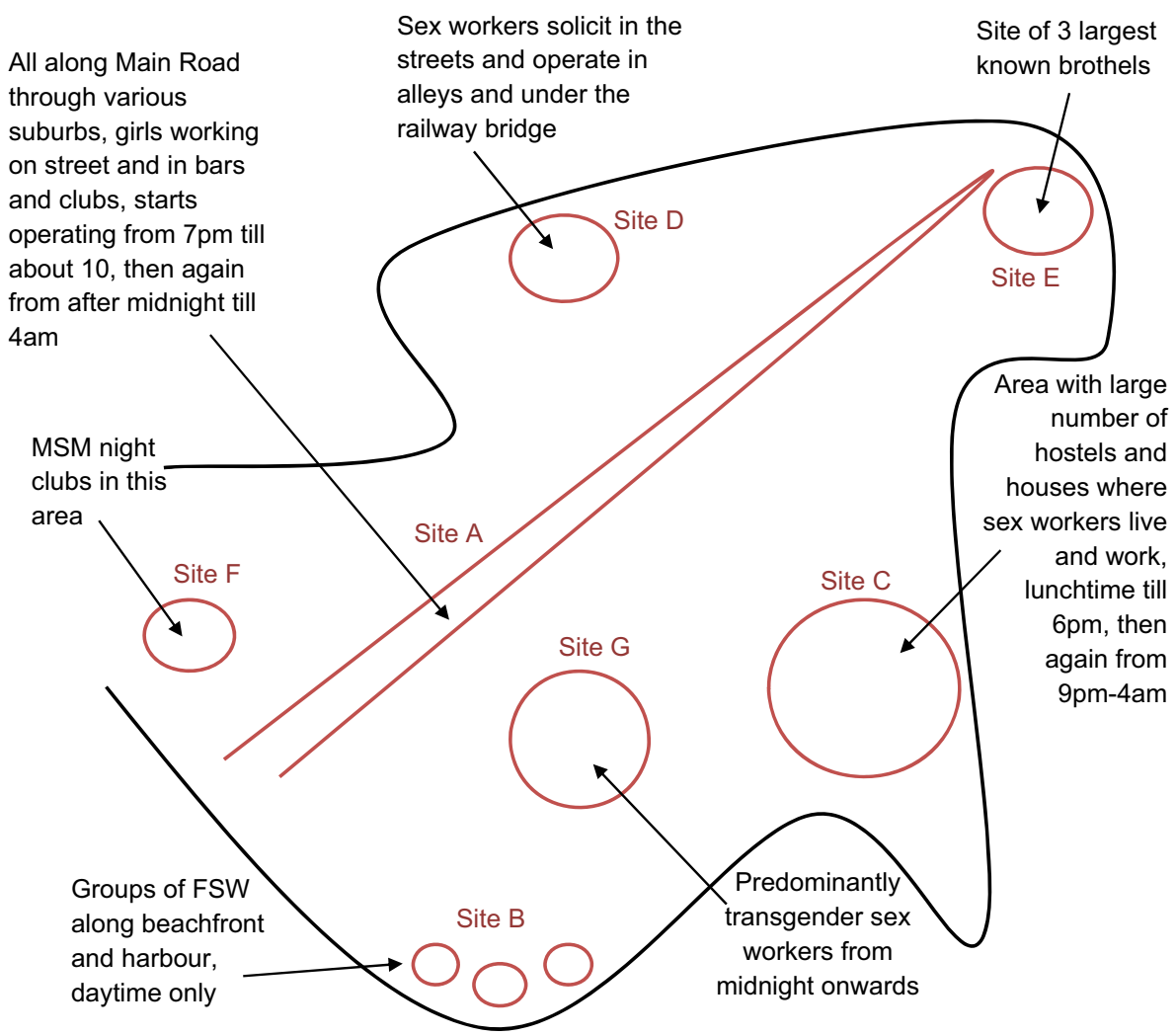

busy time, with reports of at least 6 actively operating street sections (100 sex workers x 6 streets x 3 shifts - estimate 1800). Estimating total numbers for the site is affected by some shifts being less popular than others, and the unknown number of sex worker who may be with clients and not being counted. The team must attempt to compensate for these factors, and give a best guess from the information gathered.

With variables of this nature, compensations, assumptions and estimates rely of field worker judgement, and 
Table 3 Outline of key elements of the outreach enumeration instrument, used in interactions with sex workers at hotspots

\begin{tabular}{ll}
\hline $\begin{array}{l}\text { Approximate sequence of questioning themes } \\
\text { The number of sex workers operating in the }\end{array}$ & How many sex workers work here? \\
$\begin{array}{l}\text { location } \\
\text { The extent of the location }\end{array}$ & If there are nn sex workers in this bar, do they also work in other bars? \\
& How many work in the main road from street x to street y? \\
The gender distribution & Are more of the sex workers here girls? \\
& Where do transgender and male sex workers work? \\
Other sex work locations & Where else will we meet a lot of sex workers? \\
& Approximately how many work in each of these other places? Are they the same or different \\
& people? \\
Are these other places bars or brothels, or only street work? Where do sex workers find \\
clients? \\
Wypes of locations
\end{tabular}

Enter the responses and all the places mentioned into the table below

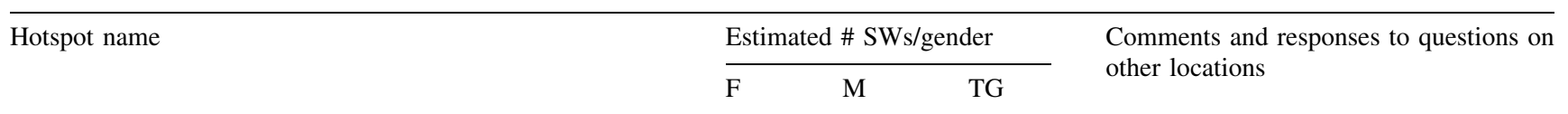

Information provided by respondent 1

Information provided by respondent 2 etc

Once data saturation for the hotspot is reached-confer with peer team and agree on an estimated for this hotspot

Continuation-if time and respondent consent permit, select from the following themes attempting to discuss all themes across the different respondents at the site:

\begin{tabular}{ll}
\hline $\begin{array}{l}\text { Sex work systems } \\
\begin{array}{l}\text { Issues experienced by sex workers, } \\
\text { probing for: }\end{array}\end{array}$ & $\begin{array}{c}\text { Are there controllers (pimps/managers) or do you work for yourselves? } \\
\text { focusing on most severe concerns) } \\
\text { Treatment by police }\end{array}$ \\
& $\begin{array}{l}\text { Describe your experiences of the police as perpetrators of violence and rape, and recourse to justice for } \\
\text { abuse by clients? } \\
\text { Describe the systems of controllers in this area. What is the situation for sex workers with regard to } \\
\text { drugs? }\end{array}$ \\
Are drugs used as a form of control? & Are sex workers being asked to take drugs with clients? \\
Describe your experiences in the public health care system & Are you able to access services? \\
Access to health care & Prompt around issues of confidentiality, discrimination and humiliation by health care workers
\end{tabular}

each estimate was explained and justified in a field debrief meeting after the field work.

\section{Site-Wide Estimates and Data Consolidation}

Smaller sites could be exhaustively surveyed in the single evening, with direct estimates for all identified hotspots. With no further extrapolation or comparison needed, the field team was able to consolidate and review the estimates at the end of the evening to discuss, agree and total the results across the different hotspots (Table 3).
In larger sites, such as major cities, where the sex worker population is larger and there is a greater dispersal of sex work sites, it was less likely that all hotspots could be visited in a rapid survey. In these cases a second focus group was convened including many of the original group, but also some additional sex workers where possible.

The follow-up FGD was used to extrapolate the direct results obtained from a sample of hotspots, to other known sex work sites in the area (Table 4). Numbers for all other sex work hotspots known to the group were estimated by comparing each with the localities that had been sampled during the field work (Fig. 2). 
Table 4 Instrument for focus group on hotspot extrapolation within larger sites, where only a sample of hotspots could be estimated through outreach interviews

Information gained during interviews at hotspots

Hotspot A has 5 houses, each with 4 rooms for sex workers

Hotspot $\mathrm{C}$ has a bar in which a known number of sex workers regularly gather

Hotspot $\mathrm{E}$ is a hotel with $\mathrm{n}$ floors $\mathrm{x} \mathrm{n}$ rooms per floor $\mathrm{x} \mathrm{n}$ sex workers per room

Hotspot $\mathrm{G}$ is used by street-based sex workers, and has $\mathrm{n}$ sex workers on each corner

A controller in Hotspot $\mathrm{J}$ has $\mathrm{n}$ sex workers in his 'care', and is known to also manage sex work at another Hotspot
Examples of appropriate questions

Are there more houses in Hotspot B than Hotspot A, or less?

Are the three bars in Hotspot D as busy for sex work as the bars in Hotspot C, or less so?

How many floors are there in the three hotels in Hotspot F? And about how many rooms per floor? How many sex workers share a room?

On which corners of Hotspot $\mathrm{H}$ do sex workers stand? Are there more sex workers there than at Hotspot G, or less?

Does Controller name have more girls in Hotspot $\mathrm{K}$ than in Hotspot $\mathrm{J}$, or less? Where do most of his girls work?
While this method provided triangulated and well-justified results for Cape Town and all smaller sites, the vast sex work industry of Johannesburg remained under-sampled after the exercise, and further outreach would have been needed for more convincing results.

\section{Data Extrapolation to a National Estimate}

Although the limited scale of the mapping exercise provided only rough national estimates, the principles behind extrapolation were explored, debated and applied. The CSIR's GIS facility provides national to local level data, including collation of the 2011 national census data. CSIR was able to provide the following statistics for each of South Africa's 1,961 local municipalities:

- Place typology (cities, regional centres, rural nodes, etc.)

- Total population size

- Number of women between the ages of 15 and 64

- Number of men employed in the mining industry

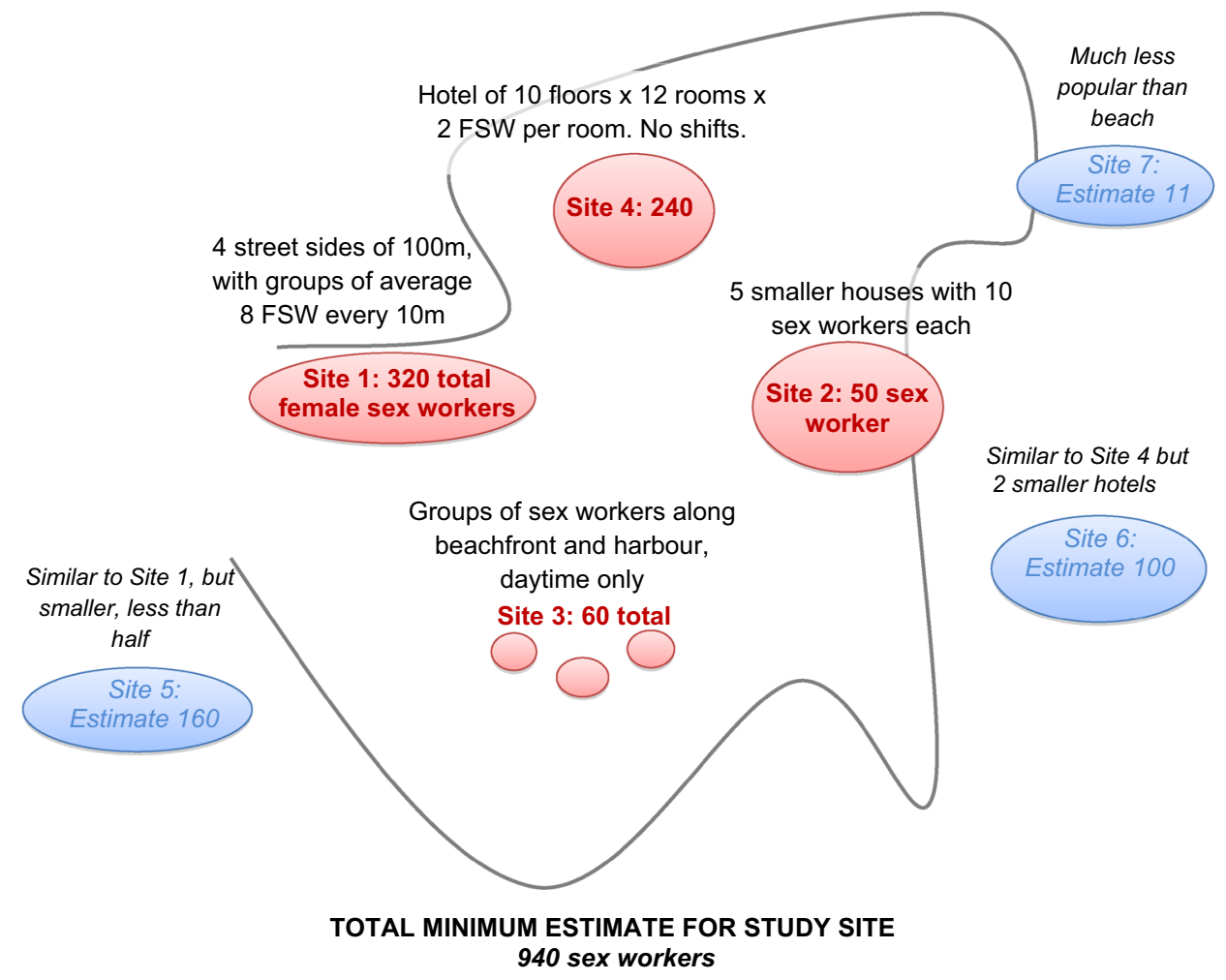

Fig. 2 Simplified example of a re-mapping exercise with directly estimated numbers in red bold, extrapolated numbers in blue italics. Actual data would include genders and a far larger number of sites (Color figure online) 
- Number of men employed in the transport industry

In consultation with a panel of experts the following process was developed for extrapolation (Table 5):

Approximate extrapolation process:

1. For the sites included in the exercise, calculate the measured sex worker percentage of adult female population (Table 1).

2. Acknowledging that the rapid survey method is likely to produce an underestimate, agree on assumptions and inflate the basic counts.

3. Using the sampled site results, apply different ratios of sex worker to adult female population for different place types, such as rural areas, small towns, metropolitan centres, etc.
4. Using the estimates from the sampled sites, apply a percentage inflation proportionate to actual mining populations, and whether the place is a border town or is located along a trucking route (Table 1). The raised sex worker ratio for high transmission areas of trucking and border towns account both for a concentration of South African sex workers, as well as large numbers of immigrant sex workers and an effective population that is higher than the census data.

5. Based on this range of assumed ratios and factors, apply a percentage of adult female population to every census point in the country, and calculate provincial and national totals.

6. Apply reasoned variations to percentage assumptions in sensitivity testing to provide minimum, moderate and maximum estimates.

Table 5 Assumptions guiding the minimum, moderate and maximum estimates

\begin{tabular}{|c|c|c|c|}
\hline & \multicolumn{3}{|c|}{$\begin{array}{l}\% \text { of adult female population used to estimate number of sex workers for different } \\
\text { location types }\end{array}$} \\
\hline & Minimum & Moderate & Maximum \\
\hline Metropolitan areas & $0.51-0.69 \%^{\mathrm{a}}$ & & $1.0 \%$ \\
\hline Cities $>200,000^{c}$ & $\begin{array}{l}0.54 \% / \text { research numbers at } \\
\text { known sites }\end{array}$ & $\begin{array}{l}0.6 \% / \text { research numbers at } \\
\text { known sites }\end{array}$ & $0.6 \%$ \\
\hline Cities $<200,000$ or other major centres ${ }^{\mathrm{d}}$ & $0.6 \%$ & $1.0 \%$ & $1.0 \%$ \\
\hline Niche or local towns ${ }^{\mathrm{e}}$ & $0.6 \%$ (or 0 if pop under 4,000 ) & $0.60 \%$ & $0.60 \%$ \\
\hline Rural areas ${ }^{\mathrm{f}}$ & $0.3 \%$ (or 0 if under 4,000$)^{9}$ & $0.3 \%$ & $0.3 \%$ \\
\hline
\end{tabular}

$\%$ of adult female population added to basic estimate for places on trucking routes, excluding metros and border towns ${ }^{\mathrm{g}}$

$\%$ of adult female population added to basic estimate in relation to number of mining employees ${ }^{\mathrm{h}}$

All inclusive set ratio used for border towns ${ }^{\mathrm{i}}$
$0.6 \%$ added to basic estimate, capped for a minimum of 10 additional sex workers to a maximum of 150

Formula: 200 sex workers/12,000 miners in hostels, assuming that $80 \%$ of miners live in hostels, for mine populations $>100$ employees

$4.5 \%$

${ }^{a}$ Assumption for minimum estimates in large metropolitans-all major metros were included in the enumeration study. The minimum and moderate national total included: 11,000 sex workers in Johannesburg; 7,500 in Cape Town and 6,300 in Durban

${ }^{\mathrm{b}}$ Assumption for maximum in metros-Vandepitte provides an average for provincial towns of $1 \%$. This ratio is also applied as a maximum for large cities

c Assumptions for minimum estimates in large cities-the enumeration study average percentage for known sites is $0.54 \%$. A maximum of $1 \%$ for smaller cities and large towns produces over-estimates that are not supported by the enumeration observations, and a reduced percentage is used

d Assumption for towns of populations under 200,000 — the estimation study gave a minimum of $0.3 \%$ of adult women, and evidence that this is undercounted by about half. Supported by Vandepitte, the minimum local or niche town percentage is estimated at $0.6 \%$

e Assumption for CSIR classified niche or local towns-none of the sampled enumeration sites was classified as a niche or local town. An estimate of $0.6 \%$ is given for these sites until more evidence is accumulated. Based on informal inquiries in two small towns with populations less than 4,000, locations with population under 4,000 are assumed to have no sex workers in the minimum estimate

${ }^{f}$ Assumption for rural areas-sex workers state that rural areas have particularly low sex worker populations, and a rate of $0.3 \%$ of adult women was applied to municipalities that are classified as rural

g Assumption for trucking-based on the enumeration results, an additional $0.3 \%$ of adult women is added to all sites on a national trucking route. This addition in not applied to the places classified as cities or border towns, since these larger estimates are expected to account for trucking trade

${ }^{\mathrm{h}}$ Assumption for the mining sector-according to the enumeration exercise each 12,000 hostel dwelling men are served by 200 sex workers. This ratio is calculated and added to the basic population ratio, using a minimum of 20 sex workers for smaller mine populations. Mine populations of under 100 are excluded as being likely to be resident and non mobile

i Assumption for border towns- the most trustworthy enumeration study estimate was the ratio of $4.5 \%$ of adult women from Pongola. A ratio of $4.5 \%$ is used for border towns in SA 
7. Appropriate follow-up is now underway to verify some of these estimates, and identify additional factors, such as tourism, access to bars and alcohol, construction or seasonal agriculture.

The extrapolation exercise itself had merit, and was greatly enhanced by the participation of a group of experts able to interrogate assumptions. A greatly increased survey sample would be needed to validate extrapolation assumptions, and to provide a far larger sample size from which to refine national population estimates.

\section{Limitations and Refinements in the Method}

Time constraints for this exercise permitted only one 24-hour period. Although comprehensive coverage of smaller or more simply delimited sites was possible within this time, an additional day or two per site is recommended. Additional time would enable active investigation of additional sites, visits to sites not reported by sex workers, and further interviews in mining hostels and similar workplaces.

The method seems to capture the majority of sex workers, but excludes sex workers operating in more discreet settings, such as private massage parlours, homebased sex workers who solicit using phone or internet, and men-who-have-sex-with-men (MSM) sex workers. Although they are in the minority, these groups have specific needs and concerns, for which targeted strategies are required.

\section{Ethical Considerations}

This population size estimation was carried out for operational support purposes as part of a national planning process, and for use by organizations providing services to sex workers. The activities are consistent with public health practice in South Africa and met the ethical standards of the participating organisations. In view of the institutional backing and oversight, and the operational nature of the exercise, formal ethical approval was not sought.

Sex work support has critical ethics concerns, and the highest standards of ethical practice were observed. Names were not noted from either focus group participants or interview respondents. No other possible personal identifiers were included in the data.

Participation was completely voluntary. Sex workers have legitimate fears of being targeted by police or censured by controllers, and are not always prepared to participate in interviews. They are also at work during outreach and survey times, and the time taken by interviewers may cost them opportunities for clients. Interviews are therefore short and the field team is encouraging, but is respectful of any signs of reluctance to participate. Consent is as much given or taken in body language and responsiveness, as in the formal verbal agreement to participate.

In this enumeration exercise most sites were supported by peer organisations that provide long-term support and services, and are available for follow-up either around sex workers' needs for services, or in case of any consequences of the outreach. Although enumeration is also important for areas without a sex workers support organisation, and can be achieved with the help of a peer from another area, there is less available follow-up support. In these cases it was important to ensure that IEC materials, branded condoms or other materials were available for distribution after interviews, providing sex workers with access to helpline contact details.

The major risk to sex workers and to their workplaces is that mapping clearly identifies a location, which could be targeted. Knowledge of exact locations of hotspots within study sites is important for programme planning, and was collected in the data, but retained only by relevant service providers. Beyond this group, size estimation maps were disseminated with great care, and only general trends and broad site numbers were more widely disseminated. Any sensitive data is either held in Impact Consulting's archive for 5-years and then destroyed, or is retained by SWEAT, which holds various sensitive sex worker information and has a code of practice for privacy.

Public contact with branded sex work outreach services obviously and immediately identifies sex workers. The visibility and transparency of the outreach enables sex workers to approach or allow themselves to be approached with awareness of the purpose of the meeting. The branding enables voluntary and informed engagement. Hotspots, by definition, include large numbers of sex workers. Street and brothel based sex workers are generally visible, and hotspots are known to the police. SWEAT and partners conduct outreach to hotspots in the course of their support, and have not observed that sites are more strongly targeted as a result of outreach. It is even possible that the visible presence with a clear sympathetic purpose, encourages more accepting attitudes to sex workers.

The global drive towards responses for most-at-risk populations will result in a range of impacts. In some cases the explicit and planned support to health and rights for sex workers and other groups may reduce harassment, as recourse to advocacy, access to legal action, knowledge of the law increase in this population. It is also possible, however, that the pressure for greater rights may create a retributive reaction, and that sex workers may face greater harassment as the established norms of police and controllers are challenged. In summary, the principles agreed for ethical engagement included: confidentiality; a visible, transparent, accessible and neutral presence, giving sex 
workers the option of whether or not to self-identifying with the exposure; and provision of free contact details for follow-up by the respondent if needed.

\section{Results}

As intended, the results have been used to inform operational planning by national health and HIV structures, and by sex worker support NGOs. They are reported fully by SANAC [10], including GIS maps of sex worker distribution and provincial estimates. Overall trends and the assumptions used for national extrapolation are reported here.

Results for municipalities were applied using the CSIR place type classifications and the adult female population size to provide a basic sex worker proportion (Table 5). These rates were varied depending on evidence of mobile men, or specifically: location of sites along in relation to major trucking routes; the number of people employed in the mining industry; and whether or not the centre is the final point before a border crossing.

Vandepitte [9] reported female sex worker rates in capital cities to range between 0.7 and $4.3 \%$ of adult women (aged 15-64). The enumeration exercise results found this to be an over-estimate for South Africa, and instead established a range for metropolitan areas of $0.5-0.7 \%$ (Table 5). The Vandepitte average of $2 \%$ for capital cities would resolve to 26,000 sex workers in Cape Town and 31,000 in Johannesburg. These numbers are far too high. Our estimate of approximately 11,000 sex workers in Johannesburg is likely to be an underestimate, but having visited the most popular sex worker hotspots, our data do not support a $2 \%$ ratio.

One possible reason for rates of $1 \%$ of adult female population in cities and larger towns resolving to overestimates could be lower sex worker numbers in the populous peri-urban low cost residential areas (townships) that surround most South African cities. The enumeration exercise showed that townships have far lower numbers of sex workers than other urban setting. Sex workers stated that they prefer not to work near their homes in these areas. For example, enumeration results estimated only 30-50 sex workers in Khayelitsha, a large township and informal settlement within the Cape Town metropolitan area.

Trucking is dispersed along all major South African routes and major truckstops are not necessarily mapped. Vandepitte [9] suggests a ratio of $2.7 \%$ sex workers to adult female population at major truckstops. With more dispersed, smaller trucking rest points, this ratio was found to be excessive for South African towns along trucking routes. Instead, the basic rate for towns on trucking routes was inflated by $0.3 \%$ of the adult female population (Table 5).
The number of people employed in the mining sector in each location is provided by CSIR (Table 1). Mining employees are assumed to be men for the purposes of the study, of whom $80 \%$ are assumed to live in single-sex hostels. A ratio of 200 sex workers for every 12,000 men resident in single sex hostels in mining centres was reported in the enumeration sites, and was used to provide the national estimate (Table 5).

Enumeration results provided an estimate of $3.5 \%$ for Musina and $4.5 \%$ for Pongola, with the Pongola results supported by a sex work health care NGO in the area. Ndola, on the DRC/Zambia border, only has a sex worker population of $2.4 \%$ of adult females [9]. A particularly high proportion of unregistered residents are present in South African border towns, and the effective population is far higher than the census data suggest. The higher ratio to official adult female population takes account of this factor (Table 5).

Hidden, home-based and high cost sex workers are not captured in the estimate method, and are assumed to represent an additional $5 \%$ to the overall female sex worker estimate. Male and transgender sex workers were also largely under-sampled, with many working in exclusive clubs or through private arrangements. Male and transgender sex workers are added to the base figures as a ratio of female sex workers, at 5 and $4 \%$ respectively.

Towns with particularly high drug and alcohol challenges, and/or large numbers of seasonal farm workers or construction workers are likely to be under-estimated by the ratios given in Table 5. Based on the enumeration exercise, however, most regional centres are known to have sex worker populations of far less than $1 \%$ of adult female population, and the suggested ratios produce over-estimates in many locations.

This set of assumptions was applied across the 1,961 categorised municipal areas, and summed to produce a minimum national estimate of around 132,000 sex workers in total (Table 6). This aligns exactly the SANAC records produced by the South African Centre for Epidemiological Modelling and Analysis [8], and aligns well with the approximate $1 \%$ of adult female population estimated for Zanzibar [20]. Most ratios are lower than those of the Vanderpitte study [9], and are far lower than the conclusions of a similarly designed Kenyan study [14] that suggests that as many as $5 \%$ of adult women could be sex workers.

\section{Conclusion}

The primary purpose of the size estimation exercise has been to estimate population and understand the distribution of sex workers and their key concerns in order to inform health and 
Table 6 Results following extrapolation: national estimate for South African sex worker population

\begin{tabular}{llll}
\hline & Total population & \multicolumn{1}{c}{ Adult female population } \\
\hline National Population $^{\mathrm{a}}$ & $51,770,097$ & $17,389,307(34 \%)$ \\
\hline & Total estimates $^{\mathrm{b}}$ & $\%$ adult female population \\
\hline Minimum estimate $^{\mathrm{c}}$ & 131,875 & $0.76 \%$ & \\
Moderate estimate $^{150,029}$ & $0.86 \%$ & Total \\
Maximum estimate & 182,040 & $1.05 \%$ & 150,029 \\
\hline Gender divisions using the moderate estimate \\
\hline Female sex workers & \multicolumn{3}{c}{137,641} \\
$5 \%$ Male & 6,882 & \\
$4 \%$ Transgender & 5,506 &
\end{tabular}

Geographic divisions using the moderate $\%$ of sex work population estimate

Urban areas of $\geq 100,000$ population

(51\% of total national population lives in these areas)

$$
72,014 \quad 48 \%
$$

Urban areas of $<100,000$ population

(27\% of total national population lives in these areas)

$$
61,512 \quad 41 \%
$$

Rural areas (22\% of total national population lives in these areas)

$$
16,503 \quad 11 \%
$$

a Source: Census 2011

b Total estimated number of sex workers, including female, male and transgender

c Minimum, moderate and maximum estimates based on extropolations for each location as outlined in Table 5

support services. The exercise has provided insights into methodology, and has tested a process using mapping and interviews, through the participation of a group of sex workers peers familiar with the area and with the distribution of sex workers. The activity has provided a starting point from which future, more accurate programmatic mapping and size estimation can be conducted.

Based on the field experience we would strongly recommend that no research be attempted without the active involvement of sex worker field team members at every stage. The process demonstrates that effective population estimates can be achieved using mapping exercises as rapid as 2-3 days per town, and that field work may have diminishing returns thereafter. Finally, the ethics and attitudes surrounding sex work investigation are paramount, including attitudes of non-judgemental concern, and acknowledgement that connection and humanity are among the most valued benefits of the exercise, while breaches of confidence or consent have potential to be among the most damaging.
The enumeration exercise demonstrated the wide range of sex work styles. There are differences in mobility from highly mobile to resident and operating entirely from a home. Sex worker may operate consistently from one street, brothel or bar, or may use a variety of different work sites. Some sex workers may travel with their clients, and move between cities and countries in the region. The implication for programming is that marketing and services should be accessible to a wide-ranging target audience, through multiple media, and in different spaces, specifically addressing the multiple entry points of sub-groups of sex workers.

Acknowledgments The time, dedication and support of sex worker guides were critical. Guides were provided and supported by SWEAT and partner organisations: Centre for Positive Care Limpopo; East London High Transmission Area Project; Re-Action Witbank; Lethabong Legal Assistance Centre; Partners in Sexual Health Beaufort West; Sisonke Sex Worker Network; Thohoyandou Victim Empowerment Program; TB/HIV Care; and Wits Reproductive Health \& HIV Institute Johannesburg. Gerbrand Mans, Centre for Scientific and Industrial Research (CSIR) Built Environment Unit, provided GIS data and mapping services. Tim Lane of the Center for AIDS Prevention Studies, UCSF, provided thorough advice and review of the methods. The steering group which provided review input and participation in an experts meeting on assumptions and extrapolation included: Mike Grasso, Tom Osmand and Zac Isdahl (UCSF); Tlangelani Shilubane (UNFPA); Andy Lambert (TB/HIV Care); Kholi Buthelezi and Duduzile Dlamini (Sisonke Sex Worker Network); Carlos Toledo and Marina Rifkin (CDC); and Andrew Scheibe (Consultant to SANAC). The project was funding and supported through SANAC.

\section{References}

1. Baral S, Beyrer C, Muessig K, et al. Burden of HIV among female sex workers in low-income and middle-income countries: a systematic review and meta-analysis. Lancet. 2012;2:538-49.

2. SANAC. National Strategic Plan on HIV, STIs, and TB 2012-2016. South African National AIDS Council. Pretoria, South Africa; 2012. http://www.sanac.org.za/nsp/the-nationalstrategic-plan. Accessed 3 May 2014.

3. UNAIDS. Protocol for programmatic mapping and size estimation for key populations. Unpublished; 2013.

4. World Health Organization. Preventing HIV among sex workers in sub-Saharan Africa: a literature review. www.who.int/hiv/pub/ sti/sex_workers_afro/en/index.html. Accessed 1 July 2014.

5. Scorgie F, Chersich MF, Ntaganira I, Gerbase A, Lule F, Lo Y. Socio-demographic characteristics and behavioral risk factors of female sex workers in sub-Saharan Africa: a systematic review. AIDS Behav. 2011;. doi:10.1007/s10461-011-9985-z.

6. Gould C, Fick N. Selling sex in Cape Town: sex work and human trafficking in a South African city. SWEAT and ISS. Cape Town: Institute for Security Studies; 2008.

7. Rees H, Beksinska ME, Dickson-Tetteh K, Ballard RC, Htun Y. Commercial sex workers in Johannesburg: risk behaviour and HIV status. S Afr J Sci. 2000;96:283-4.

8. SACEMA. The modes of transmission of HIV in South Africa: an HIV incidence modelling component of the South African Know Your Epidemic, Know Your Response synthesis. Unpublished; 2009. 
9. Vandepitte J, Lyerla R, Dallabetta G, Crabbé F, Alary M, Buvé A. Estimates of the number of female sex workers in different regions of the world. Sex Transm Infect. 2006;82(Suppl 3):iii18iii25.

10. Konstant TL, Rangasami J, Stewart M. Estimating the size of the sex worker population in South Africa. SWEAT and SANAC; 2013. http://www.sanac.org.za/resources/doc_download/37-national-sexworkers-report. Accessed 1 July 2014.

11. UCSF, CDC, UCT and ANOVA. Integrated biological and behavioral surveillance surveys with population size estimation among female sex workers and long distance truck drivers in KwaZulu Natal, South Africa: protocol. University of California San Francisco, Center for Disease Control, University of Cape Town and ANOVA. 2013. Unpublished.

12. Ferguson AG, Morris CN. Mapping transactional sex on the Northern Corridor highway in Kenya. Health Place. 2007;13(2): 504-19.

13. Zhang D, Wang L, Lv F, et al. Advantages and challenges of using census and multiplier methods to estimate the number of female sex workers in a Chinese city. AIDS Care. 2007;19:17-9.

14. Odek WO, Githuka GN, Avery L, Njoroge PK, Kasonde L, et al. Estimating the size of the female sex worker population in Kenya to inform HIV prevention programming. PLoS One. 2014;9(3): e89180. doi:10.1371/journal.pone.0089180.

15. Emmanuel F, Blanchard J, Zaheer HA, Reza T, Holte-McKenzie M, HASP team. The HIV/AIDS surveillance project mapping approach: an innovative approach for mapping and size estimation for groups at a higher risk of HIV in Pakistan. AIDS. 2010;24(Suppl 2):S77-84. doi:10.1097/01.aids.0000386737.25296.c4.

16. Frank Ove, Snijders Tom. Estimating the size of hidden populations using snowball sampling. J Off Stat. 1994;10(1):53-67.

17. Vuylsteke B, Vandenhoudt H, Langat L, et al. Capture-recapture for estimating the size of the female sex worker population in three cities in Côte d'Ivoire and in Kisumu, western Kenya. Trop Med Int Health. 2010;15(12):1537-43. doi:10.1111/j.1365-3156. 2010.02654.x.

18. Natalie MPH, Behets FM, Vaovola G, et al. Participatory mapping of sex trade and enumeration of sex workers using capturerecapture methodology in Diego-Suarez, Madagascar. Sex Transm Dis. 2003;30:664-70.

19. Morison L, Weiss HA, Buvé A, et al. Commercial sex and the spread of HIV in four cities in sub-Saharan Africa. AIDS. 2001;15(Suppl 4):S61-9.

20. Khalid FJ, Hamad FM, Othman AA, et al. Estimating the number of people who inject drugs, female sex workers, and men who have sex with men, Unguja Island, Zanzibar: results and synthesis of multiple methods. AIDS Behav. 2014;18(Suppl 1):S25-31. doi:10.1007/s10461-013-0517-x. 